\title{
Participation, Growth and Social Poverty: Social Capital in a Homo- geneous Society
}

\author{
Angelo Antoci ${ }^{*}, 1$, Pier Luigi Sacco ${ }^{2}$ and Paolo Vanin ${ }^{3}$ \\ ${ }^{I}$ DEIR, University of Sassari, Italy \\ ${ }^{2} D A D I$, IUAV, Venice, Italy \\ ${ }^{3}$ Department of Economics, University of Padova, Italy
}

\begin{abstract}
We introduce social capital accumulation into a neoclassical model, showing how it differs from physical and human capital accumulation. We take the view that social capital is crucial to the enjoyment of socially provided goods and that it is mainly accumulated by means of participation to social activities. Under-investment in social capital may lead a growing economy to fall into a social poverty trap. We argue that this risk is particularly relevant for advanced societies.
\end{abstract}

JEL-Classification: D62, I31, J22, O41, Z13.

Keywords: Social capital, self-protection choices, social poverty traps.

\section{INTRODUCTION}

Growth theory has been typically concerned with the process of physical and human capital accumulation. More recently, much attention has been devoted to the role played for growth by social capital, i.e. by those accumulated productive resources that are incorporated in the social structure of a society (rather than in physical goods or in single individuals). By its own nature, the process of accumulation of social capital is quite different from that of other forms of capital, because a large part of its payoffs is not privately appropriable. Thus, individuals may not have an adequate incentive to accumulate it.

We investigate the dynamics of social capital accumulation within a neoclassical framework and show that under-investment in social capital may lead an economy to a social poverty trap. We take the view that social capital is crucial to the enjoyment of socially provided goods and that it is mainly accumulated by means of participation to social activities. Such participation, and the goods it provides, may be substituted for by some private activities, which generate private goods. Since most private goods enter in the GNP, whereas many socially provided goods don't, this substitution process may foster growth exactly as the flip side of a process of social impoverishment. The choice of how to allocate time between social and private activities has two external effects: a direct one, on the 'productivity' of other people's social activities at a given point in time, and a

*Address correspondence to this author at the DEIR, University of Sassari, Italy; Tel: +39 0792017 313; Fax: +39 0792017 312;

E-mail: angelo.antoci@virgilio.it

${ }^{\S}$ We would like to thank Antonio Cabrales, Antonio Ciccone, Benedetto Gui, Giorgio Rampa and Joel Shapiro for helpful discussions and comments, as well as the audience to seminars in Padova, Pavia and Barcelona, with the usual disclaimer. cumulative one, on social capital accumulation over time. If individuals are not able to internalize these externalities, the overall outcome of their choices may be sub-optimal, notwithstanding the fact that they are generating economic growth.

We interpret the possibility that growth and social impoverishment move together as relevant in the medium run, i.e. in a time horizon in which the choice of time allocation may change significantly, but which still is shorter than the very long run, since in the latter social impoverishment renders growth unsustainable. We consider a society with homogeneous population, which empirically turns out to be the most favorable environment for social capital accumulation. Moreover, we disregard any contribution of social capital to the production of private goods, although such contributions are empirically relevant. As a consequence, the risk of falling into a social poverty trap that we find in our model would hold $a$ fortiori if one takes into account a segmented population and the relationship between social capital and private production. The process we are investigating is particularly relevant for affluent societies, where pressure on time and other factors may indeed lead to a substitution of time-saving private activities for timeintensive social ones. In a companion paper [Antoci, Sacco and Vanin (2007)], we study the same process within the context of an evolutionary model. Both the neoclassical and the evolutionary approach lead to analogous conclusions. In another companion paper [Antoci, Sacco and Vanin (2005)], we show that the basic results we find here also extend to a more complex set-up, with both private and social capital accumulation. Therefore, while in the present context we model growth just in terms of an expansion in private production, explicit consideration of a private accumulable asset would not change the picture. The advantage of 
focusing on social capital alone is that in the present paper we are able to characterize the dynamic analysis for any possible parameter configuration.

In Section 2 we consider the literature on social capital and growth and relate our work to it. Section 3 investigates the link between growth and social impoverishment. Section 4 displays the model and its results. Section 5 concludes.

\section{SOCIAL CAPITAL AND GROWTH}

In the last two decades economists have been paying a lot of attention to the role of social capital for growth. The term 'social capital' was rendered popular by Coleman and Putnam and the World Bank (2008) has an entire electronic library on the topic. Coleman $(1988,1990)$ mentions as examples of social capital the level of trust and the information potential incorporated in relations, the existence of civic norms with effective sanctions, and the presence of hierarchical and horizontal relations and organizations. Putnam (1993) makes the point that a richer network of civic engagement and of horizontal organizations (this way he defines social capital) explains much of the economic advantage of Northern Italy over Southern Italy. Putnam (1995 and 2000) argues that social capital has been declining in the U.S. in the last thirty years, mainly due to the impact of television and to the aging of a generation with a strong civic commitment ${ }^{1}$. Different authors emphasize different aspects of social capital and the literature may be divided into two main branches, according to whether social capital is defined at the individual level or at the group level ${ }^{2}$.

To the first branch, pioneered by Coleman, belong, for instance, Glaeser, Laibson and Sacerdote (2002) and DiPasquale and Glaeser (1999), who investigate individual social capital and focus on individual investment in social skills and in connections to others, respectively. Both social skills and social connections yield a private return: for instance, Becker (1981) offers a classical example of the returns to social skills in the marriage market and Granovetter (1973) shows the relevance of 'weak' connections to find a job.

Group level definitions of social capital focus on the economic impact either of trust and civic norms or of voluntary associations and horizontal organizations ${ }^{3}$. Paldam and Svendsen (2000) summarize a line of thought that goes from Arrow (1971) to Fukuyama (1995) and emphasize that the density of trust in a group or in a society influences

\footnotetext{
${ }^{1}$ Costa and Kahn (2003) show that the decline in the social capital produced outside home is mainly due to rising community heterogeneity (especially income inequality), whereas the decline of the social capital produced at home is mainly explained by women's increased labor force participation rate.

${ }^{2}$ At the highest level of generality, Narayan (1999) defines social capital as 'the norms and social relations embedded in the social structures of societies that enable people to coordinate action to achieve desired goals'.

${ }^{3}$ Collier (1998) distinguishes among social capital created in different groups, i.e., at different institutional levels: family, firm, government and civil society. Narayan (1999) points out that the relation between governmental services and social capital is not univocally of substitution or of complementarity. Bowles and Gintis (2002) make similar considerations, but they criticize the term 'social capital'.
}

economic outcomes because it determines how easily people work together.

The empirical relevance of social capital for growth has been highlighted, among others, by Knack and Keefer (1997), Temple and Johnson (1998), Zak and Knack (2001) and Knack (2003). The broad message of this literature is that generalized trust has a strong and robust positive impact on growth ${ }^{4}$. On the other side, although social participation fosters trust, its growth impact does not appear to be relevant. In other words, most effects of social participation remain confined to the social sphere ${ }^{5}$, whereas trust directly affects growth.

Different forms of social capital may have different effects. Social capital tends to exert positive aggregate effects when trust, norms and networks that foster cooperation extend beyond primary, ethnic, linguistic or even income groups and form 'bridges' among different groups. This last point is made with particular strength by Narayan (1999), who observes that the same links that keep together the members of a group may also exclude the non-members, and who displays an analytical framework to study 'bonding' (intra-group) and 'bridging' (inter-group) links. On a similar line, Annen (2001) adapts Spagnolo's (1999) model to study the different impact of 'inclusive' and 'exclusive' social capital (defined in terms of entry costs into social networks). $\mathrm{He}$ argues that inclusive social capital can combine high gains from trade with low enforcement costs, thereby raising economic performance, whereas exclusive social capital may impede growth by limiting gains from trade and diffusion of new ideas, as well as by generating rent-seeking. The different impact of different social networks on private activities with positive external effects is also emphasized by Nepal, Bohara and Berrens (2007). Yet they focus on private contributions to environmental capital, whereas our focus is on social capital accumulation.

A number of contributions tackle the issue of how social capital, in its various forms, is accumulated. Glaeser, Laibson and Sacerdote (2002) show theoretically and empirically that individuals invest in social skills in the same way as they do in human capital ${ }^{6}$. DiPasquale and Glaeser (1999) display a model predicting that homeowners invest more than renters both in social connections and in local amenities. The data confirm this prediction and show that the main reason is that homeownership decreases mobility. Alesina and La Ferrara (2002), Zak and Knack (2001), Knack and Keefer (1997) and Glaeser, Laibson, Scheinkman and Soutter (2000) all find empirically that social heterogeneity and social distance, in terms of income, 'race'

\footnotetext{
${ }^{4}$ The empirical problem of measuring trust has been deeply addressed by Glaeser et al. (2000), who find that standard survey questions about trust provide a better measure of trustworthiness than of trusting behavior. However, Berg, Dickhaut and McCabe (1995) present experimental evidence that higher trust increases trustworthiness. Indeed, these two aspects are highly correlated.

5 Just to give two examples, Leung (2002) finds that several forms of social participation reduce the probability of becoming a delinquent and Buonanno, Montolio and Vanin (2008) find that social capital reduces property crimes.

${ }^{6}$ Since they call 'social capital' the social component of human capital, their result is not surprising.
} 
and ethnic origin, reduce trust. Alesina and La Ferrara (2000) focus on the effect of heterogeneity on participation in associational activities like religious groups, sport groups, hobby clubs, unions, and so on. Using data for metropolitan areas in the U.S. from 1974 to 1994 and controlling for individual and community characteristics, they show that social participation is higher where income inequality, 'racial' segmentation and ethnic segmentation are lower'.

Summing up, heterogeneity has a negative effect on both social participation and trust, but while trust has a positive effect on economic outcomes, participation has mainly social effects. We restrict our attention to a homogeneous society and to the time allocation choice between private and social activities. We argue that aggregate social participation today increases the 'productivity' of the time spent in social activities both today and tomorrow, since it contributes to the formation of a 'better', socially more rewarding environment. In other words, it contributes to social capital accumulation. Investment in social capital takes here the primary form of time investment in social activities and its costs can be measured in terms of forgone private consumption.

As mentioned above, Glaeser, Laibson and Sacerdote (2002) display a neoclassical model of investment in social capital. The main difference between their model and ours arises from the fact that what they call 'social capital' is the social component of individual human capital, whereas we look at social capital from an aggregate point of view. In our framework, individuals forgo private consumption and undertake social activities primarily because they seek socially provided goods. Social capital accumulation emerges as a by-product, as an external effect ${ }^{8}$. Such aspects make the process of social capital accumulation quite different from physical and human capital accumulation. We emphasize this point and show how it translates into an otherwise standard neoclassical model.

Routledge and von Amsberg (2003) present a model which is very close in spirit to ours to study the effects of technological change on labor mobility and, as a by-product, on social capital, but they do not present an explicit dynamic model of social capital accumulation, which is precisely one of the main contributions of our paper.

\section{GROWTH AND SOCIAL IMPOVERISHMENT}

We start with the consideration that individuals have material and relational needs. Most of the first ones may be

\footnotetext{
${ }^{7}$ This happens in the North/Northwest of the U.S., the opposite features appearing in the South/Southeast. Moreover, looking at participation in different kinds of groups, they find that heterogeneity matters less for participation in groups with a relatively high degree of excludability or a low degree of close interaction among members. Finally, they find that 'racial' segmentation matters more for individuals more averse to 'racial' mixing.

${ }^{8}$ Indeed, it is a common feature of non-material forms of capital that investment and consumption come close to one another: think e.g. of knowledge. In the case of social capital something similar happens: to some extent individuals participate to social activities with an intentional purpose to invest in relations, but to some extent participation is more a consumption than an investment activity, where the goods consumed are 'relational' rather than private.
}

satisfied by private consumption activities, whereas the second ones are mostly satisfied by socially provided goods. These goods are referred to by Uhlaner (1989) as 'relational goods'; other authors, e.g. Corneo and Jeanne (1999), prefer to speak of socially provided private goods ${ }^{9}$. We make use of either terminology. Examples of relational goods include friendship and enjoyment of shared leisure ${ }^{10}$. Two peculiar aspects of relational goods are that they cannot be enjoyed alone and that it is mostly very difficult to separate their 'production' form their 'consumption', since they easily coincide. Indeed, not only 'consumers' and 'producers' are the same agents, but social participation 'produces' relational goods at the same time that it lets participants 'consume' them, i.e. enjoy them: relational goods are a special case of Cornes and Sandler's (1984) joint production model.

Relational goods are scarce goods because their enjoyment is subject to a time budget constraint (possibly also to a monetary budget constraint, but we focus on the first one). They are brought about by participation to social activities, which are time-intensive. At least since Becker's (1965) pioneering contribution, we know that time is a scarce resource and that an increased pressure on it (an increase in the value of time) leads to a substitution of time-saving activities for time-intensive ones ${ }^{11}$. Growth itself brings about an increase in the opportunity cost of time, which is clearly more expensive today in advanced societies than it used to be in the past ${ }^{12}$. An early account of this process is provided by Hirsch (1976):

As the subjective cost of time rises, pressure for specific balancing of personal advantage in social relationships will increase. Perception of the time spent in social relationships as a cost is itself a product of privatized affluence. The effect is to whittle down the amount of friendship and social contact. The huge increase in personal mobility in modern economies adds to the problem by making sociability more of a public and less of a private good. The more people move, the lower are the chances of social contacts being reciprocated directly on a bilateral basis (Hirsch 1976, p. 80).

The relevance of the last point, i.e., of personal mobility, for the substitution of private for social activities, is also investigated by Schiff (1992 and 1999) and by the above mentioned contributions by Routledge and von Amsberg (2003) and by DiPasquale and Glaeser (1999). When this substitution takes place, we may observe at the same time social impoverishment and private growth, as, according to Putnam (2000), we have indeed observed in the U.S. in the last three decades of the XX century. The overall effect in terms of well-being may be either negative (so that we can

\footnotetext{
${ }^{9}$ They argue that the desire of such goods may lead individuals to invest more in their own human capital and may thus have a positive impact on growth.

${ }_{10}$ Survey data on time uses, on the frequency of friends meeting and on participation to various associations, easily available in several countries, may be used to construct empirical proxies of relational goods.

${ }^{11}$ Fast-foods are successful because they are fast, not because they offer good food!

${ }_{12}^{12}$ It may be argued that socially provided goods become scarce in affluent societies, when growth, increasing the value of time, renders the time budget constraint binding.
} 
speak of social poverty traps), because efficiency gains may be outweighted by the loss in social capital, or positive, when the reverse happens ${ }^{13}$.

For the sake of concreteness, in the model we identify private activities with the time spent working or consuming and social activities with the time spent in social participation outside the job. Of course, we are aware of the socializing value of working, as well as of the fact that working is almost never a truly private activity, since it requires cooperation with other people, but, as shown empirically by Alesina and La Ferrara (2000), among employed people there is a negative relation between the time spent in social participation and in private production. Moreover, our interpretation corresponds to the standard view that labor time is a bad and not a good and, since in our model there is no unemployment, we feel that this is a good first approximation.

\section{THE MODEL}

\section{Preferences and Technology}

We consider an economy constituted by a continuous population of identical individuals (indicated as $\tau \in[0,1]$ ), who 'every day' (we model 'days' in continuous time, indicate them with $t$ and normalize their length to 1) choose how to allocate their time between private and social activities. In day $t$, the fraction of time spent by individual $\tau$ in social activities, $s_{\tau}(t)$, provides him or her utility in the form of a socially provided good $B_{\tau}(t)$, whose amount depends, besides on $s_{\tau}(t)$, on average social participation, $\bar{s}(t)=\int_{0}^{1} s_{\tau}(t) \mathrm{d} \tau$, and on the 'quality' of the social environment inherited from the past, i.e., on social capital $K_{s}(t)$. We assume that there is a private good $C_{s \tau}(t)$ which is a perfect substitute of the relational good $B_{\tau}(t)$ and we denote $l_{s \tau}(t)$ the fraction of time spent by $\tau$ to produce and consume $C_{s \tau}(t)$. Finally, individuals satisfy their subsistence needs by devoting time $l_{\tau}(t)$ to produce and consume a subsistence good $C_{\tau}(t)$. We think of the activities of production and consumption of $C_{s \tau}(t)$ and of $C_{\tau}(t)$ as of private activities. We assume that $C_{s \tau}(t)$ and $C_{\tau}(t)$ are not accumulable and let the instantaneous individual utility function be:

$u_{\tau}(t)=\ln \left[C_{\tau}(t)\right]+b \ln \left[B_{\tau}(t)+a C_{s \tau}(t)\right]$,

where $a>0$ is the marginal rate of substitution between $B_{\tau}(t)$ and $C_{s \tau}(t)$, and $b>0$ captures the relative weight attributed to non-subsistence $v s$ subsistence needs.

\footnotetext{
${ }^{13}$ We acknowledge that mobility might improve sorting and the potential quality of social matches, but we emphasize that it may reduce the time available to build relationship-specific social capital and it may substantially fasten its depreciation. This corresponds to the common experience of migrants and of scholars studying or working abroad.
}

We assume linear technologies in the production of private goods and a Cobb-Douglas technology in the production of the relational good:

$$
\begin{aligned}
& C_{\tau}(t)=\alpha l_{\tau}(t), \quad \alpha>0, \\
& C_{s \tau}(t)=\beta l_{s \tau}(t), \quad \beta>0, \\
& B_{\tau}(t)=\sigma s_{\tau}(t)^{\gamma} \bar{s}(t)^{\delta} K_{s}(t)^{\varepsilon}, \quad \sigma, \gamma, \delta, \varepsilon>0 .
\end{aligned}
$$

Social capital in this economy is accumulated as individuals spend time in social activities and generate durable relations, which become the basis for the development of trust, civic norms and voluntary associations. It seems therefore natural to model aggregate 'investment' in social capital $I_{s}(t)$ as an increasing function of the quantity of relational goods produced (and consumed) at a certain time in the economy, according to a sort of learning-bydoing mechanism. Perhaps the easiest way to model such 'investment' is the following:

$$
I_{s}(t)=\int_{0}^{1} B_{\tau}(t) \mathrm{d} \tau
$$

Notice that we use the term 'investment' in analogy with what drives the accumulation of other forms of capital. Nevertheless, it has to be stressed that here individuals do not 'invest' time in social activities with the purpose of accumulating social capital, but rather to enjoy the relational goods they get through participation to social activities. Indeed, they consider social capital as a public good and they do not internalize the effects of their choices on its accumulation. Such accumulation appears therefore just as a byproduct of activities with different aims. This is indeed one of the first intuitions about social capital, already pointed out by Coleman.

Since relations deteriorate if they are not taken care of, the full dynamics of social capital has to incorporate a depreciation rate $\eta \geq 0$ :

$\dot{K}_{s}(t)=I_{s}(t)-\eta K_{s}(t)$.

\section{Individual Maximization Problem}

Let $r$ be the rate at which individual $\tau$ discounts future utility. The individual's maximization problem in our economy is then:

$$
\begin{aligned}
& \max _{s_{\tau}, l_{\tau}, l_{s \tau} \int_{0}^{\infty} u_{\tau}(t) e^{-r t} \mathrm{~d} t, \quad \text { s.t. }} \\
& s_{\tau}(t), l_{\tau}(t), l_{s \tau}(t) \geq 0, \\
& s_{\tau}(t)+l_{s \tau}(t)+l_{\tau}(t)=1, \\
& \dot{K}_{s}(t)=I_{s}(t)-\eta K_{s}(t) .
\end{aligned}
$$

The associated Hamiltonian function is:

$$
H\left[s_{\tau}(t), l_{\tau}(t), l_{s \tau}(t), K_{s}(t), \lambda\right]=u_{\tau}(t)+\lambda\left[I_{s}(t)-\eta K_{s}(t)\right] .
$$

Since the population is continuous, the choice of $s_{\tau}(t)$ by a single individual has no impact on $I_{s}(t)$, so that each 
individual considers $I_{s}(t)$ as exogenous (notice that the same is true for $\bar{s}(t))$. Hence, $\lambda$, the shadow-price of $K_{s}$, does not appear in the conditions for the maximization of the Hamiltonian function with respect to the control variables. As a consequence, these conditions coincide with those obtained for the maximization of $u_{\tau}(t)$ in each instant of time with respect to the same control variables. We therefore omit the time index and, since individuals are identical, also the index $\tau$, and solve the representative individual's pointwise problem:

$\max _{s, l, l_{s}} u=\ln (\alpha l)+b \ln \left(\sigma s^{\gamma} \bar{s}^{\delta} K_{s}^{\varepsilon}+a \beta l_{s}\right) \quad$ s.t.

$s, l, l_{s} \geq 0, \quad s+l+l_{s}=1$.

Remark 1 Since constraints (9) determine a compact set and the objective function $u$ is continuous, for any level of $K_{s}$ problem (8) - (9) has a solution.

The Lagrangean function is:

$L\left(s, l, l_{s}, \theta\right)=\ln (\alpha l)+b \ln \left(\sigma s^{\gamma} \bar{s}^{\delta} K_{s}^{\varepsilon}+a \beta l_{s}\right)-\theta\left(s+l+l_{s}-1\right)$

and the solution must satisfy the following first order conditions (where we exploit the fact that ex post $\bar{s}=s$ ):

$\frac{\partial L}{\partial l}=\frac{1}{l}-\theta \leq 0 ; \quad \frac{\partial L}{\partial l} \cdot l=0, \quad l \geq 0 ;$

$\frac{\partial L}{\partial s}=\frac{b \sigma \gamma s^{\gamma+\delta-1} K_{s}^{\varepsilon}}{\sigma s^{\gamma+\delta} K_{s}^{\varepsilon}+a \beta l}-\theta \leq 0 ; \quad \frac{\partial L}{\partial s} \cdot s=0, \quad s \geq 0 ;$

$\frac{\partial L}{\partial l_{s}}=\frac{a b \beta}{\sigma s^{\gamma+\delta} K_{s}^{\varepsilon}+a \beta l_{s}}-\theta \leq 0 ; \quad \frac{\partial L}{\partial l_{s}} \cdot l_{s}=0, \quad l_{s} \geq 0 ;$

$s+l+l_{s}=1$.

From the expression of $u$ in problem (8) it is immediate to conclude that the representative agent allocates his or her time in such a way that $\left[l>0 \wedge\left(s>0 \vee l_{s}>0\right)\right]$ always holds (so that we have $0<l<1$ ). Now, condition (10) implies $\frac{1}{l}=\theta$. A straightforward substitution in the first order conditions then shows that a necessary condition to have both $s>0$ and $l_{s}>0$ is:

$\sigma \gamma s^{\gamma+\delta-1} K_{s}^{\varepsilon}-\alpha \beta=0$.

It is easy to show that condition (14) may define the representative agent's optimal choice only if $\gamma+\delta<1$, whereas for $\gamma+\delta \geq 1$ the representative agent chooses either $s$ or $l_{s}$ equal to zero ${ }^{14}$. We can thus separate these two cases.

Case (a): $\gamma+\delta \geq 1$

\footnotetext{
${ }^{14}$ If $\gamma+\delta>1$, condition (14) determines a local minimum instead of a local maximum, whereas, if $\gamma+\delta=1, \frac{\partial L}{\partial s}$ is independent of $s$ and again we have either $s=0$ or $l_{s}=0$.
}

If the representative agent chooses $s=0, l_{s}=1-l$, it must hold that $\frac{\partial L}{\partial l_{s}}=\frac{b}{1-l}-\frac{1}{l}=0$, so that:

$l=\frac{1}{1+b}, \quad l_{s}=\frac{b}{1+b}$.

If the choice is instead such that $l_{s}=0, s=1-l$, it must hold that $\frac{\partial L}{\partial s}=\frac{b \gamma}{1-l}-\frac{1}{l}=0$, so that:

$l=\frac{1}{1+b \gamma}, \quad s=\frac{b \gamma}{1+b \gamma}$.

Straightforward substitution of these values in the utility function yields that choice (16) is strictly better than choice (15), if and only if:

$K_{s}>\hat{K}_{s} \equiv\left[\frac{a b \beta(1+b \gamma)^{\gamma+\delta+\frac{1}{b}}}{\sigma(b \gamma)^{\gamma+\delta}(1+b)^{1+\frac{1}{b}}}\right]^{\frac{1}{\varepsilon}}$.

For $K_{s}<\hat{K}_{s}$ the representative agent chooses $s=0$ and $l_{s}>0$, whereas for $K_{s}>\hat{K}_{s}$ he or she chooses $s>0$ and $l_{s}=0^{15}$.

Case (b): $\gamma+\delta<1$

When $\quad \gamma+\delta<1, \quad \lim _{s \rightarrow 0} \frac{\partial B}{\partial s}=\infty, \quad$ so that the representative individual always chooses $s>0$, whatever the value of $K_{s}$. Equation (14) then implies that for $K_{s}$ sufficiently high $l_{s}=0$ is chosen, for $K_{s}$ sufficiently low instead $l_{s}>0$. The critical threshold $\tilde{K}_{s}$ may be determined by plugging $l_{s}=0$ and $\frac{1}{l}=\theta$ into equations (11) and (12) and by equalizing $\frac{\partial L}{\partial s}=\frac{\partial L}{\partial l_{s}}=0$, so to obtain the value of $K_{s}$ for which $l_{s}=0$ and $s=1-l$, but the non-negativity constraint on $s$ is not yet binding. This yields:

$$
\begin{aligned}
\frac{\partial L}{\partial s} & =\frac{b \sigma \gamma s^{\gamma+\delta-1} K_{s}^{\varepsilon}}{\sigma s^{\gamma+\delta} K_{s}^{\varepsilon}}-\frac{1}{l}=\frac{b \gamma}{s}-\frac{1}{1-s}=0, \\
\frac{\partial L}{\partial l_{s}} & =\frac{a b \beta}{\sigma s^{\gamma+\delta} K_{s}^{\varepsilon}}-\frac{1}{l}=\frac{a b \beta}{\sigma s^{\gamma+\delta} K_{s}^{\varepsilon}}-\frac{1}{1-s}=0 .
\end{aligned}
$$

Equation (18) implies $s=\frac{b \gamma}{1+b \gamma}$, which, substituted in equation (19), yields:

${ }^{15}$ For $K_{s}=\hat{K}_{s}$ the representative agent is indifferent between the two choices; whatever the choice, in $K_{s}=\hat{K}_{s}$ dynamics (22) below is discontinuous from right. Notice that one could speculate on the effect of the parameters on $\hat{K}_{s}$, but at the present stage they do not constitute our main focus. The same will be valid with $\tilde{K}_{s}$ below. 
$K_{s}=\tilde{K}_{s} \equiv\left[\frac{a b \beta}{\sigma(b \gamma)^{\gamma+\delta}(1+b \gamma)^{1-\gamma-\delta}}\right]^{\frac{1}{\varepsilon}}$.

For $K_{s}<\tilde{K}_{s}$ the choice of $s$ and $l_{s}$ is determined by equation (14) as:

$s=\left(\frac{\sigma \gamma}{a \beta} K_{s}^{\varepsilon}\right)^{\frac{1}{1-\gamma-\delta}}$.

For $K_{s} \geq \tilde{K}_{s}$ it is determined by equation (16).

\section{Social Participation, Growth and Social Poverty Traps}

Taking into account the representative individual's equilibrium choices, dynamics (6) becomes:

$\dot{K}_{s}(t)=\sigma s\left(K_{s}\right)^{\gamma+\delta} K_{s}^{\varepsilon}-\eta K_{s}$.

where $s\left(K_{s}\right)$ is the following function ${ }^{16}$ :

Case (a): $\gamma+\delta \geq 1: s\left(K_{s}\right)= \begin{cases}0 & K_{s}<\hat{K}_{s} \\ \frac{b \gamma}{1+b \gamma} & K_{s} \geq \hat{K}_{s}\end{cases}$

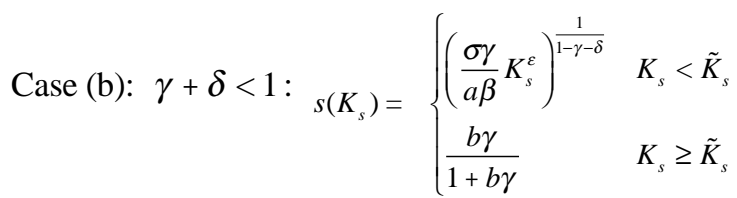

Remark $2 K_{s}=0$ is always a fixed point of dynamics (22) and in such state the representative agent chooses $s=0$.

This means that both social capital and social participation are null, whereas production and consumption of private goods reach their maximum. If relational goods played no role in determining well-being, this would be the best possible outcome, but if we introduce relational concerns in the utility function, such a result may be completely reversed, as the next remark makes clear.

Remark 3 The fixed point with $K_{s}=0$ is Paretodominated by any other point in which $K_{s}>0$ and the representative agent chooses $s>0$. Moreover, if $K_{s}^{*}$ and $K_{s}^{* *}$ are two fixed points such that $K_{s}^{* *}>K_{s}^{*}$, then $K_{s}^{*}$ is Paretodominated by $K_{s}^{* *}$.

The first part of Remark 3 follows from a straightforward substitution in the utility function. The intuition behind the second statement is as well straightforward, since an increase in the level of $K_{s}$ amounts to an expansion of the production and consumption possibility set. In fact, any choice of

\footnotetext{
${ }^{16}$ Notice that in equation (23), when $K_{s}=\hat{K}_{s}$, the representative individual is indifferent between $s=0$ and $s=\frac{b \gamma}{1+b \gamma}$, but the specific value of $s$ chosen in a single point is not relevant for dynamics (22); in equation (24) this problem does not even arise, since it defines in that case $s\left(K_{s}\right)$ is a continuous function.
}

$s, l, l_{s}$ that is possible under $K_{s}^{*}$ is still possible under $K_{s}^{* *}$; moreover, it provides at least the same utility and, if $s>0$, a strictly higher utility. We can therefore introduce the following definition.

Definition 4 Let $K_{s}^{*}$ be the highest value of $K_{s}$ in a locally attracting fixed point of dynamics (22). We call 'social poverty trap' any other fixed point such that $K_{s}<K_{s}^{*}$, if existing.

It is perhaps useful to stress again at this point that we are ignoring the possible double link between social capital and 'private' production activities: empirical research shows that social capital increases private production and growth; on the other hand, the-job interaction might generate social capital, in the same way as social interaction. The first link, if considered, would reinforce our definition of social poverty traps, whereas the second one would make it less compelling. Recall from our discussion in the previous section that, if we neglect unemployment, a negative relation emerges between working time and social participation, so that the first link seems to prevail. An additional argument may come from the observation that voluntary social participation usually involves a higher degree of internal pro-social motivation than working activities, which plays a key role in the development of trust. The empirical and the motivational arguments, taken together, make us confident that the omitted link is more likely to reinforce our definition of social poverty traps than to weaken it.

\section{Dynamics of Social Capital Accumulation}

In the Appendix we classify dynamics (22) under (23) (24), taking into account all the possible combinations of parameter values. Here we focus on just one case of particular interest.

Assumption 5 Assume $\gamma+\delta<1, \varepsilon<1, \gamma+\delta+\varepsilon>1$ and let $\eta$ be small ${ }^{17}$.

In this case, as shown in Fig. (14) of the Appendix, that we reproduce here for ease of reading, there exist two locally attracting fixed points, one with no social capital, which constitutes a social poverty trap, and a Pareto-superior one with positive social capital ${ }^{18}$. Their attraction basins are separated by a repulsive fixed point. If initial social capital is above this threshold, the economy converges to the fixed point with a positive stock of social capital. Now observe that along decreasing paths of $K_{s}$ private production and consumption increase, whereas social participation decreases.

\footnotetext{
${ }^{17} \gamma+\delta<1$ means that we are in case (b): intuitively, we can think of this assumption in terms of decreasing returns to scale of social participation, even though this is not literally correct, since social participation is a fraction $s \in[0,1] . \varepsilon<1$ means that social capital has decreasing returns to scale in the production of $B \cdot \gamma+\delta+\varepsilon>1$ resembles the idea of aggregate increasing returns to scale in the production of $B$. A small $\eta$ means that social capital does not depreciate too fast.

${ }^{18}$ In the figures we call $f\left(K_{s}\right) \equiv \sigma\left[s\left(K_{s}\right)\right]^{\gamma+\delta} K_{s}^{\varepsilon}$, where $s\left(K_{s}\right)$ is given by equations (23) and (24), so that $\dot{K}_{s}=f\left(K_{s}\right)-\eta K_{s}$.
} 
Therefore, if convergence takes place from below, we have social development at the expenses of private activities; if it takes place from above, along the convergence path we observe an expansion of private activities. If initial social capital is below the threshold, the economy experiences an expansion of private activities along the convergence path, but converges to the Pareto-inferior fixed point, i.e., to the social poverty trap. The role of social capital depreciation rate is to move the threshold: the faster social capital depreciates, the larger the attraction basin of the social poverty trap. Indeed, if $\eta$ is too high, the attractor with positive social capital disappears.

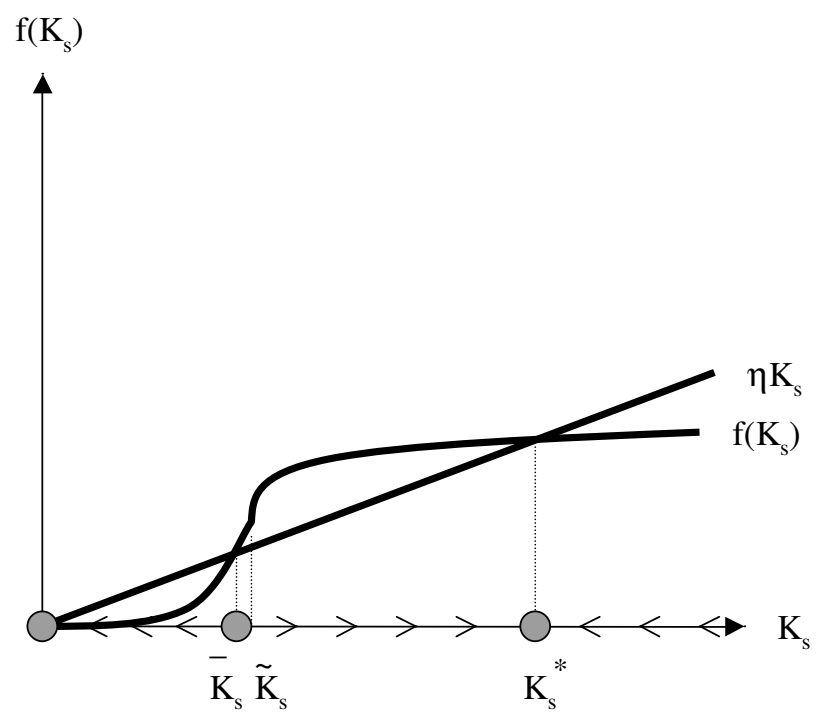

The possibility of two attractors, one of which is a social poverty trap.

\section{Policy Speculations}

Even though the present framework does not allow to formulate solid policy conclusions, it does allow to make some policy speculations. It seems plausible to think that the speed of social capital depreciation is strictly related to the degree in individual mobility of a society. From this point of view, our framework leads, through a different way, to the same point of Schiff's (1992) analysis of the impact of labor mobility on social capital and welfare. Our result is also in accordance to Schiff's (1999 and 2002) discussion of the difference between the two main forms of factor mobility: migration and trade. While the former one has relevant and often overlooked social consequences, the same is not true for the latter one. The bottom line of this discussion is not to argue against individual mobility, since its positive aspects have not been taken into account here. Rather, it is to stress that the evaluation of its well-being consequences should take into account its effects on social capital and enjoyment of relational goods.

As we have seen, besides the problem generated by a high social capital depreciation rate, there is the problem determined by the presence of externalities. If policy has any scope from this point of view, it should be to let individuals internalize the direct and the indirect externality of social participation, i.e. take into account the effect of their own participation on average social participation today, and thereby on the amount of socially provided goods they enjoy themselves today, and on social capital accumulation, and thereby on the amount of relational goods they will be able to enjoy tomorrow. Such aims can probably be achieved to some extent through educational policy. Notice that reward schemes of a Pigouvian kind could in principle solve the direct externality problem, since this would only require information about technology, but to solve the cumulative externality problem the public authority needs to know the individual intertemporal discount rate. Moreover, besides all the traditional problems associated to these policy instruments, a further problem is generated by the role of intrinsic motivations in determining social participation. As pointed out by Gneezy and Rustichini (2000), incentives may have the effect of changing the way people frame a situation (for instance they can let individuals re-interpret a nonmarket good in market terms), so that they can crowd out intrinsic (or social) motivations. Since voluntary social participation does not belong to the class of market activities, one should be careful in applying incentives schemes that have been designed to operate within the scope of the market.

\section{CONCLUSION}

The basic argument driving the present model starts with the recognition that individual well-being depends on satisfaction of both material and relational needs. The first ones may be satisfied to a great extent through private activities, whereas the second ones may only be satisfied by participating to social activities. The outcome of private activities typically enters in the GDP, but much of the outcome of social activities, namely what we call relational goods, does not. Moreover, social participation generates a direct externality, in that it raises the 'productivity' of the time other individuals spend in social activities, and a cumulative externality, in that it contributes to the formation of social capital. Social capital positively increases the returns to both private and social activities, but we just concentrate on the latter effect, arguing that our basic results would still hold if we considered the former one as well. Our basic result can be stated as follows: even with a homogeneous population of optimizing agents, an economy may get stuck in a social poverty trap, i.e., in a Paretodominated equilibrium, if its initial stock of social capital is too low or if the 'depreciation' rate of social capital is too high. Along the transition path towards a social poverty trap an economy may experience at the same time private growth, registered in national accounting, and social impoverishment. The reason why optimizing agents may fail to reach the optimum is straightforward: they are not able to internalize the direct and cumulative external effects of their actions. In particular, we focus on the possibility of substituting some kinds of private goods for relational goods. When individuals operate such substitution they do not calculate that some positive externalities go lost. We argue that this substitution process may be of empirical relevance especially for advanced economies: since social activities are typically 
time-intensive, the increasing pressure on time experienced by advanced societies provides a strong incentive to substitute time-saving private activity for social participation. Moreover, the process may be self-feeding, because when an economy is experiencing at the same time private growth and a decline in social participation and social capital, the time spent in social activities becomes both more expensive (in terms of opportunity cost) and less 'productive' (in terms of relational goods). This framework allows policy speculations on the impact of labor mobility on well-being through its effect on social capital depreciation rate and on the possibility and the difficulty to provide adequate incentives to social participation.

In two companion papers [Antoci, Sacco and Vanin (2007 and 2005)] we investigate this process within the framework of an evolutionary growth model and introducing private capital accumulation besides social capital accumulation, respectively. Both extensions confirm the validity of the basic result that under-investment in social capital may lead a growing economy to fall into a social poverty trap. Empirical tests of the theory and theoretical study of a heterogeneous population are in our future research agenda.

\section{APPENDIX}

Case (a): $\gamma+\delta \geq 1$

In this case equations (22) and (23) imply:

$\dot{K}_{s}= \begin{cases}-\eta K_{s} & K_{s}<\hat{K}_{s} \\ \sigma\left(\frac{b \gamma}{1+b \gamma}\right)^{\gamma+\delta} K_{s}^{\varepsilon}-\eta K_{s} & K_{s} \geq \hat{K}_{s}\end{cases}$

Notice first that if $\eta=0$, i.e. if we neglect the role of 'depreciation' of social capital, we have that every value $K_{s} \in\left[0, \hat{K}_{s}\right)$ is a fixed point, whereas starting from higher initial values of social capital $K_{s}(0) \geq \hat{K}_{s}$ we have $K_{s} \rightarrow \infty$. The extension of the locus of social poverty traps is then determined by the parameters that affect $\hat{K}_{s}$, identified in equation (17).

Let us now assume that social capital 'depreciates', i.e. $\eta>0{ }^{19}$. We can then distinguish the following subcases.

(a.1): $\varepsilon>1$. With increasing marginal 'productivity' of $K_{s}$, we have the three cases illustrated in Figs. (2-4), there are always two attractors, $K_{s}=0$ and $K_{s}=\infty$. For low values of $\eta$ (Figs. 1,2) the respective attraction basins are separated by $\hat{K}_{s}$ (in Fig. (2) $\hat{K}_{s}$ is a repulsive fixed point, in Fig. (1) it is not a fixed point); for high values of $\eta$ (Fig. 3) they are separated by a repulsive fixed point $\bar{K}_{s}>\hat{K}_{s}$, which

${ }^{19}$ The assumption of linear depreciation, proportional to the existing stock of $K_{s}$, is the easiest and most immediate one, but other forms of depreciation, possibly more realistic, could be conceived as well. means that a higher 'depreciation rate' expands the basin of attraction of social poverty.

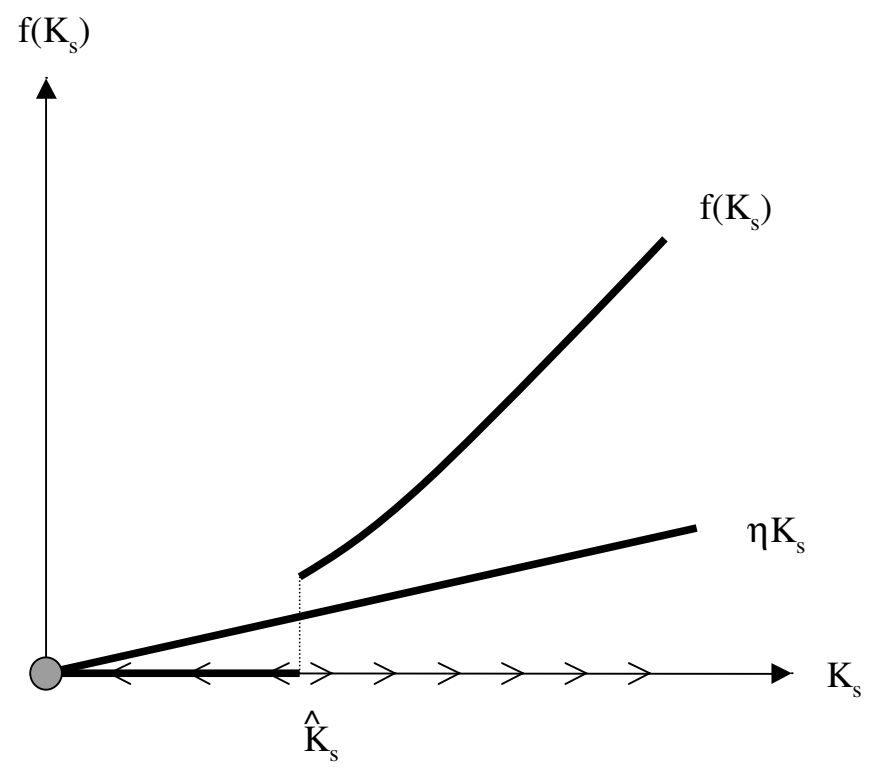

Fig. (1).

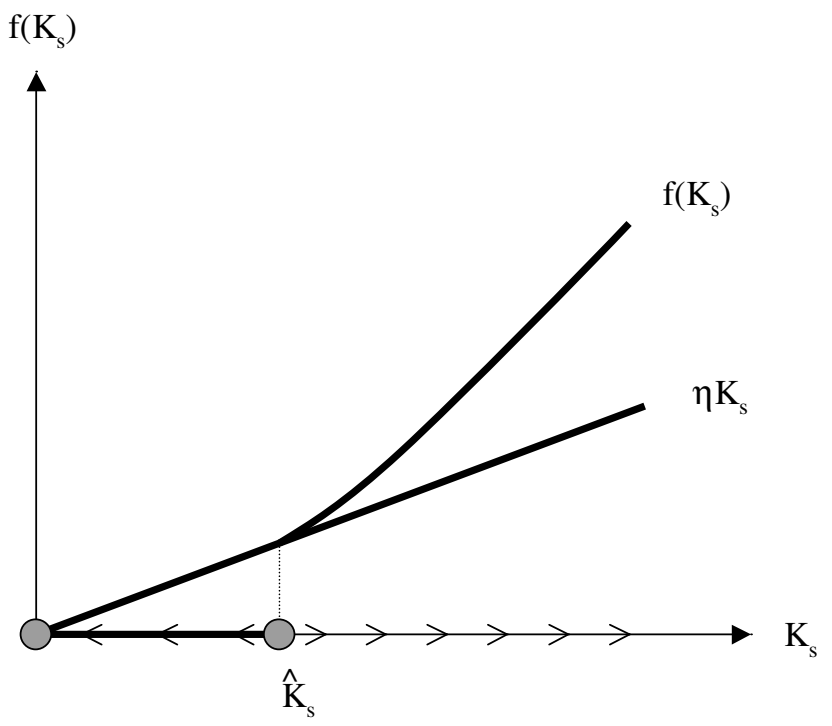

Fig. (2).

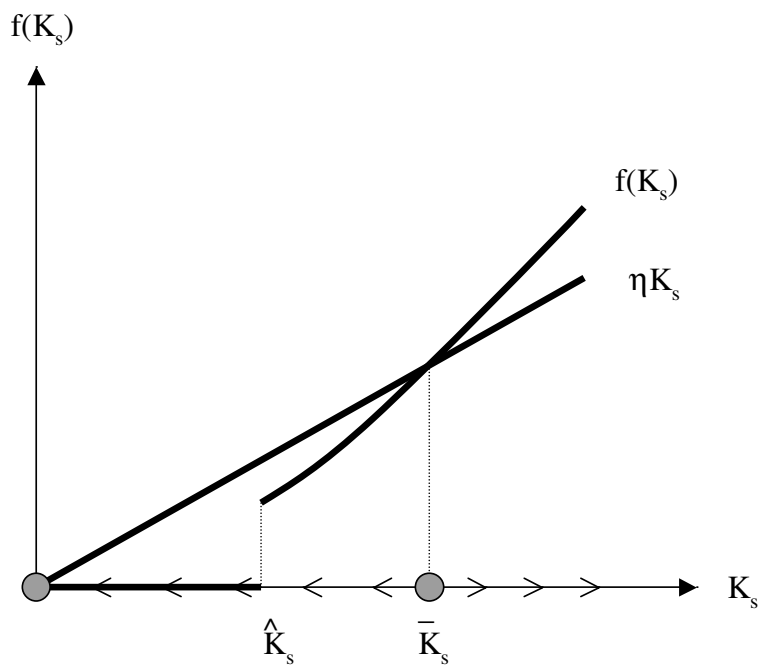

Fig. (3). 
(a.2): $\varepsilon=1$. With constant returns to scale of social capital in the 'production' of relational goods, low values of $\eta$ (Fig. 4) are again associated with the presence of the attractors $K_{s}=0$ and $K_{s}=\infty$, separated by $\hat{K}_{s}$ (which is not a fixed point). The intermediate value $\eta=\sigma\left(\frac{b \gamma}{1+b \gamma}\right)^{\gamma+\delta}$

(Fig. 5) renders all $K_{s} \in\left[\hat{K}_{s}, \infty\right)$ fixed points; $\left[0, \hat{K}_{s}\right)$ is the attraction basin of the social poverty trap $K_{s}=0$. Finally, for higher values of $\eta$ (Fig. 6), $K_{s}=0$ becomes globally attracting. Notice that in this last case we do not speak any more of a social poverty trap, since there is no way the economy can avoid it, unless the primitives, i.e. preferences and technology, change. On the contrary, when social poverty traps are present, i.e. when there are two or more locally attracting fixed points, in which one of them the economy ends up depends crucially on its initial endowment of social capital: different previous histories, reflected in different initial endowments, explain why otherwise identical economies may end up with completely different social and cultural structures, in terms of allocation of time between the social and the private sphere.

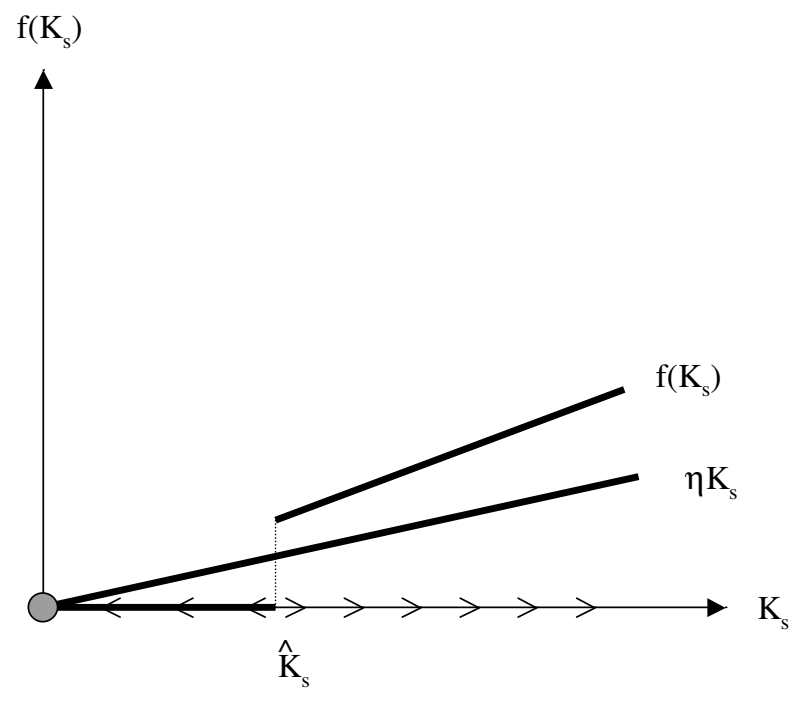

Fig. (4).

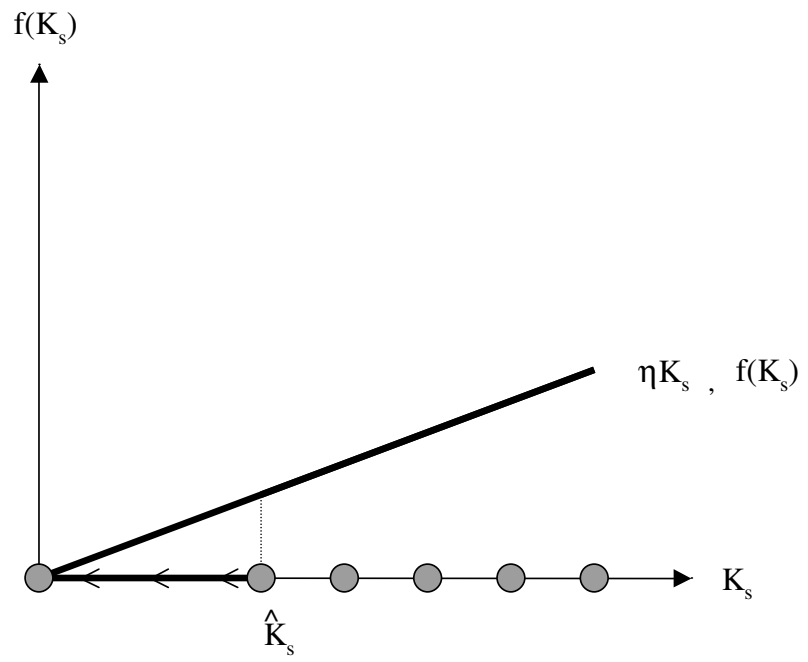

Fig. (5).

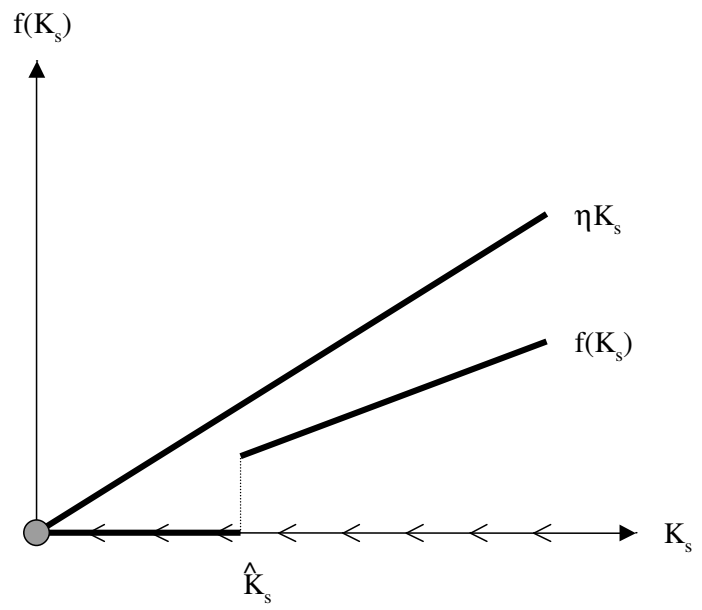

Fig. (6).

(a.3): $\varepsilon<1$. With decreasing returns to scale to social capital, $K_{s}=\infty$ is never an attractor. For low values of $\eta$ (Fig. 7) there are two locally attracting fixed points, $K_{s}=0$ and $\bar{K}_{s}>\hat{K}_{s}$, whose attraction basins are respectively $\left[0, \hat{K}_{s}\right)$ and $\left[\hat{K}_{s}, \infty\right)$; as $\eta$ increases, first $\bar{K}_{s}$ converges to $\hat{K}_{s}$, until it reaches this value (Fig. 8), then, for even higher values of $\eta$ (Fig. 9), $K_{s}=0$ becomes the only, globally attracting fixed point.

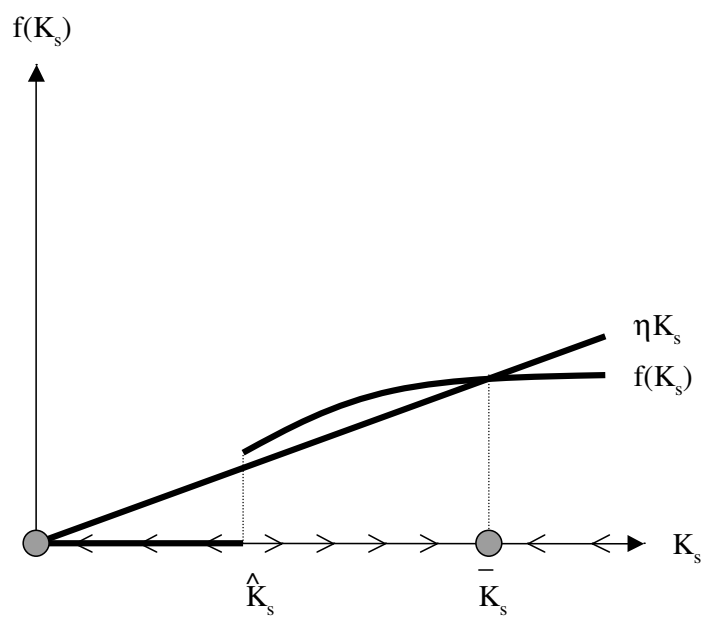

Fig. (7).

\section{$f\left(K_{s}\right)$}

Fig. (8).

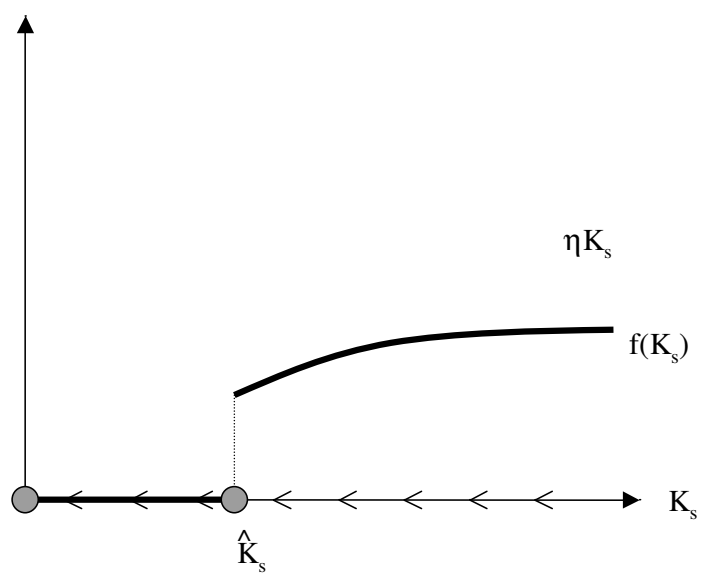




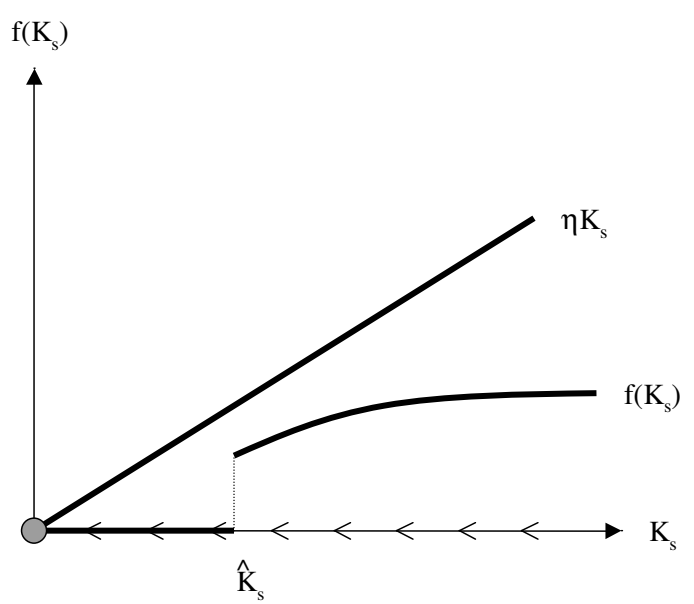

Fig. (9).

Case (b): $\gamma+\delta<1$

In this case equations (22) and (24) imply:

$$
\dot{K}_{s}= \begin{cases}\sigma\left(\frac{\sigma \gamma}{a \beta}\right)^{\frac{\gamma+\delta}{1-\gamma-\delta}} K_{s}^{\frac{1}{1-\gamma-\delta}}-\eta K_{s} & K_{s}<\tilde{K}_{s} \\ \sigma\left(\frac{b \gamma}{1+b \gamma}\right)^{\gamma+\delta} K_{s}^{\varepsilon}-\eta K_{s} & K_{s} \geq \tilde{K}_{s}\end{cases}
$$

It is easy to show that equation (26) defines $\dot{K}_{s}$ as a continuous function of $K_{s}$ (in particular, it is continuous at $\tilde{K}_{s}$, even if it is not derivable at this point). Let us now consider the exponent of $K_{s}$ for $K_{s}<\tilde{K}_{s}$; since $\varepsilon \frac{1}{1-\gamma-\delta}>\varepsilon$, then if $\varepsilon \geq 1$, it holds $\varepsilon \frac{1}{1-\gamma-\delta}>1$; if $\varepsilon<1$, it holds $\varepsilon \frac{1}{1-\gamma-\delta} \geq 1 \Leftrightarrow \gamma+\delta+\varepsilon \geq 1$, i.e. when the function $G\left(s, \bar{s}, K_{s}\right)=\sigma s^{\gamma} \bar{s}^{\delta} K_{s}^{\varepsilon}$ has either constant returns to scale (case $\gamma+\delta+\varepsilon=1$ ) or increasing returns to scale (case $\gamma+\delta+\varepsilon>1$ ). In the following classification we consider all these cases and omit for simplicity those ones which are not 'robust', meaning that a slight change in the parameters modifies qualitatively dynamics (26).

(b.1): $\varepsilon>1$. There always exists a repulsive fixed point $\bar{K}_{s}$ which separates the attraction basin of the social poverty trap $K_{s}=0$ from the states of the economy starting from which $K_{s} \rightarrow \infty$ (Fig. 10); $\bar{K}_{s}$ may be greater, equal or less than $\tilde{K}_{s}$. An increase of the 'depreciation' rate $\eta$ has the effect of expanding the attraction basin of $K_{s}=0$.

(b.2): $\varepsilon=1$. In this case, for low values of $\eta$ (Fig. 11) a repulsive fixed point $\bar{K}_{s}<\tilde{K}_{s}$ separates the attraction basin of the social poverty trap $K_{s}=0$ from that of $K_{s}=\infty$. As $\eta$ increases, $\bar{K}_{s}$ converges to $\tilde{K}_{s}$; when it reaches this value (Fig. 12), all $K_{s} \in\left(\tilde{K}_{s}, \infty\right)$ are fixed points, whereas $\left(0, \tilde{K}_{s}\right)$ is the attraction basin of the social poverty trap $K_{s}=0$. For even higher values of $\eta$ (Fig. 13), $K_{s}=0$ becomes the only, globally attracting fixed point.

$\mathrm{f}\left(\mathrm{K}_{\mathrm{s}}\right)$

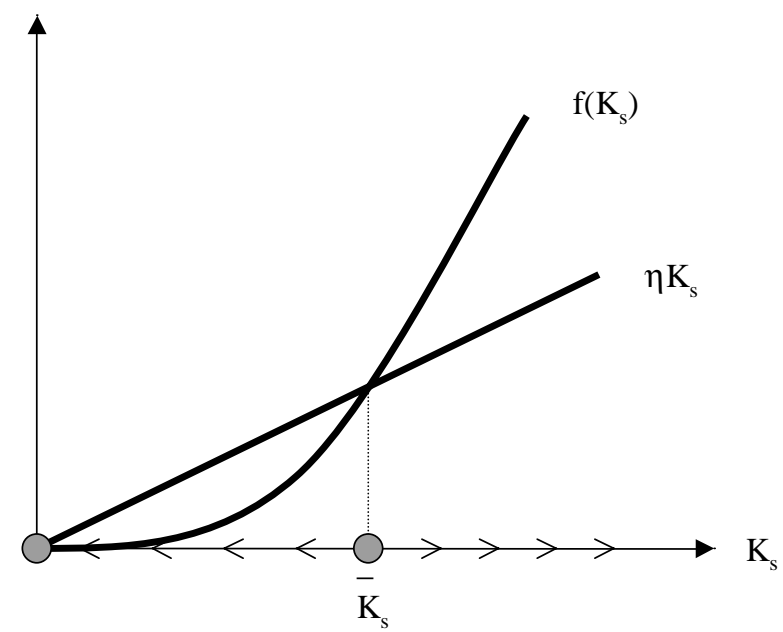

Fig. (10).

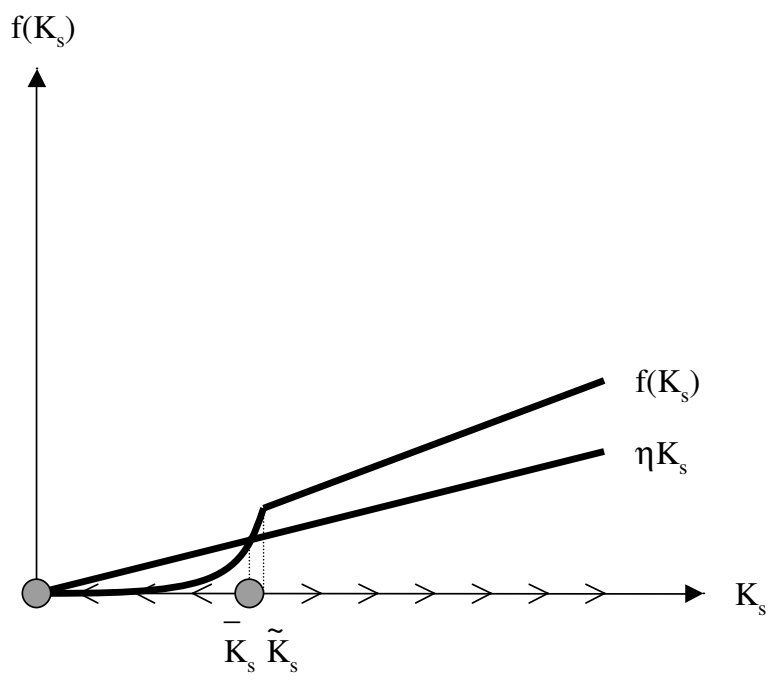

Fig. (11).

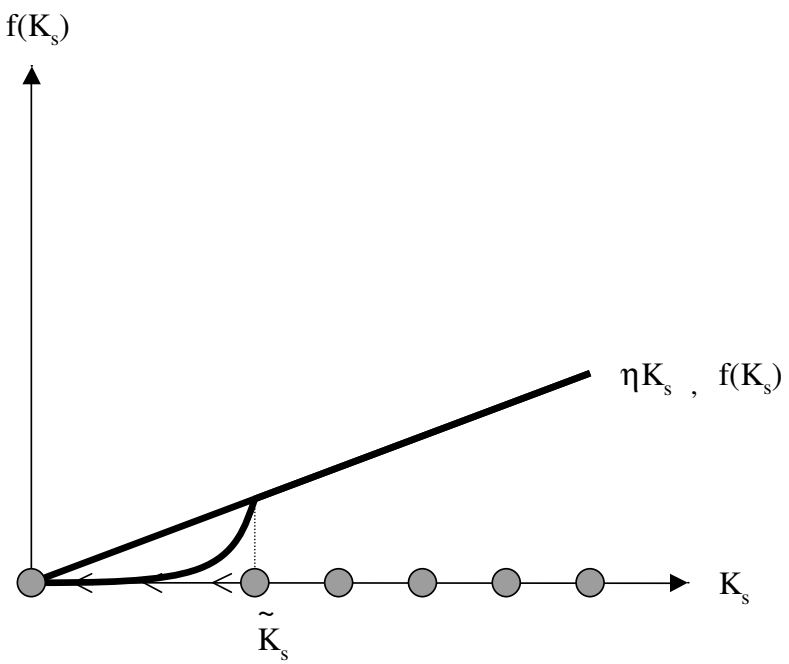

Fig. (12). 


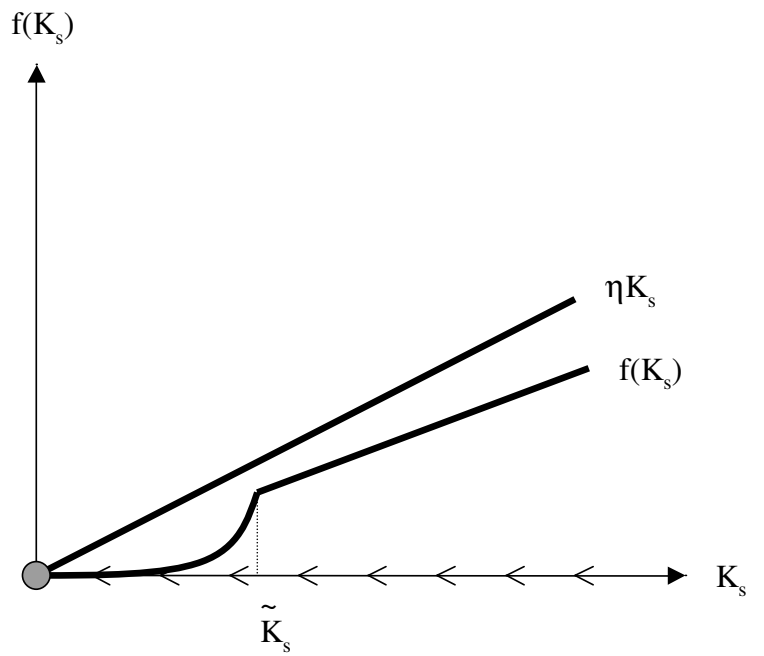

Fig. (13).

(b.3): $\varepsilon<1$. We have now to distinguish among the following subcases.

(b.3.1): $\gamma+\delta+\varepsilon>1$. In this case, as in case (a.3), $K_{s}=\infty$ is never an attractor. For low values of $\eta$ (Fig. 14) there are two locally attracting fixed points, $K_{s}=0$ and $K_{s}^{*}>\tilde{K}_{s}$, whose attraction basins are separated by a repulsive fixed point $\bar{K}_{s}<\tilde{K}_{s}$ and are respectively $\left[0, \bar{K}_{s}\right)$ and $\left(\bar{K}_{s}, \infty\right)$. As $\eta$ increases, $\bar{K}_{s}$ and $K_{s}^{*}$ converge to each other, until the situation described in Fig. (15) is reached. For even higher values of $\eta$ (Fig. 16), $K_{s}=0$ becomes the only globally attracting fixed point.

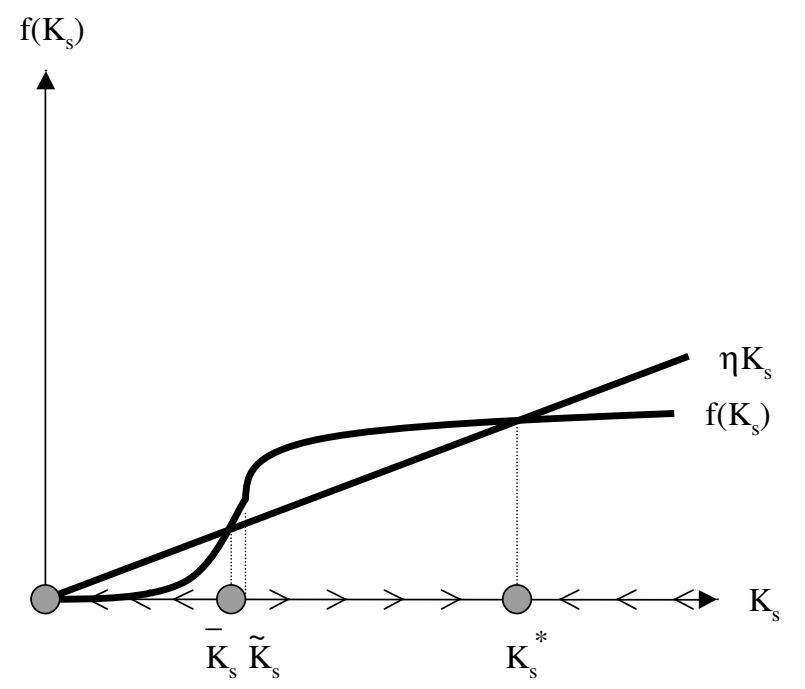

Fig. (14).

(b.3.2): $\gamma+\delta+\varepsilon=1$. In this case, once again, $K_{s}=\infty$ is never an attractor. For low $\eta$ (Fig. 17), there exists a fixed point $\bar{K}_{s}>\tilde{K}_{s}$ whose attraction basin is $(0, \infty)$ : any economy with a positive initial social capital ends up there; of course, $K_{s}=0$ is still a fixed point, but it is now repulsive. As $\eta$ grows, $\bar{K}_{s}$ converges to $\tilde{K}_{s}$ and when it reaches it (Fig. 18) we have a segment $\left[0, \tilde{K}_{s}\right.$ ) of fixed points which correspond to social poverty traps and the fixed point $\tilde{K}_{s}$ whose basin of attraction is $\left[\tilde{K}_{s}, \infty\right)$. Higher values of $\eta$ (Fig. 19) render $K_{s}=0$ globally attracting.

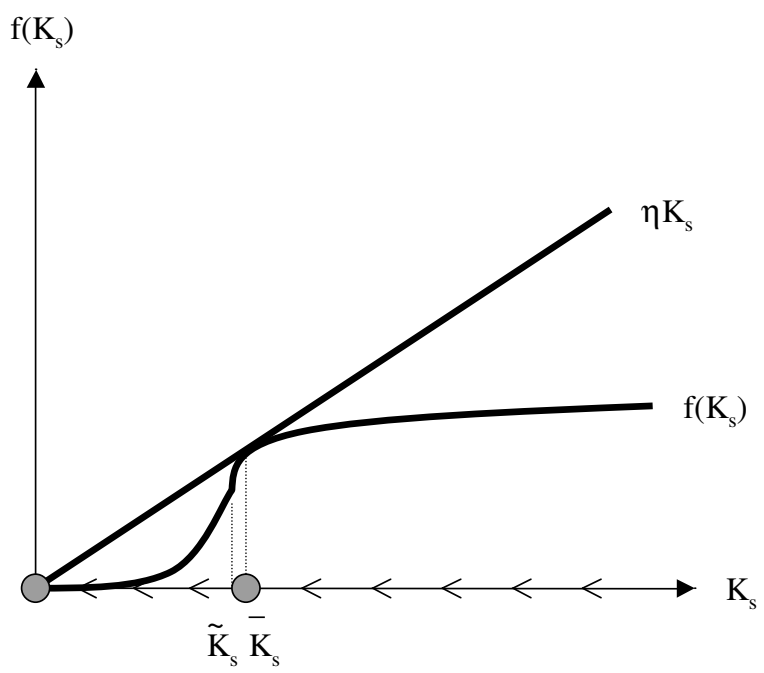

Fig. (15).

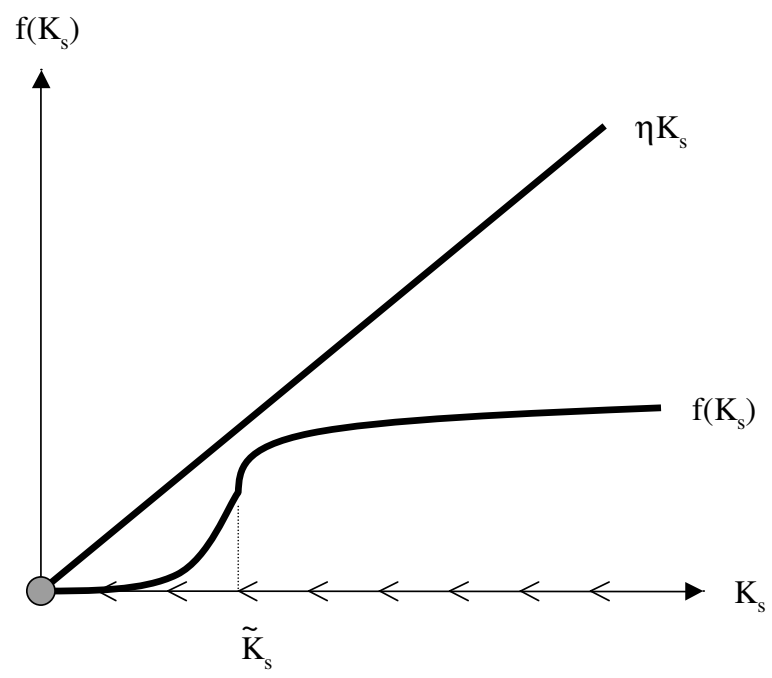

Fig. (16).

$\mathrm{f}\left(\mathrm{K}_{\mathrm{s}}\right)$

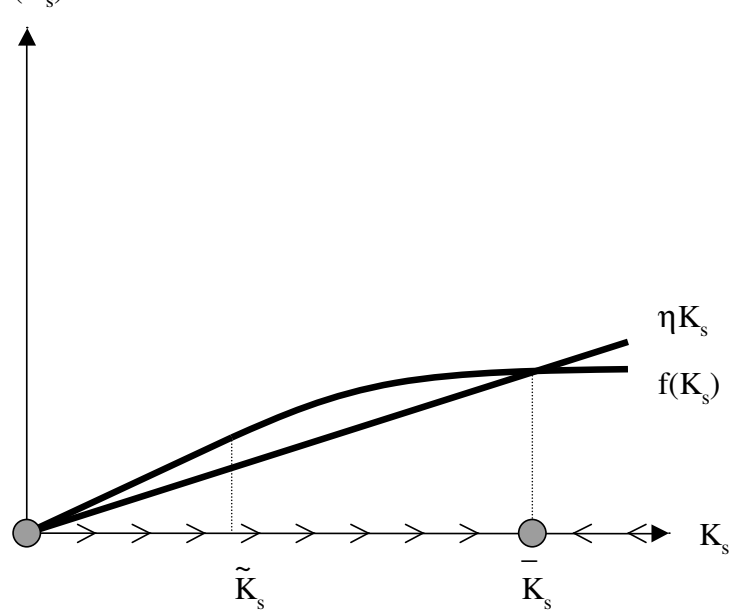

Fig. (17). 


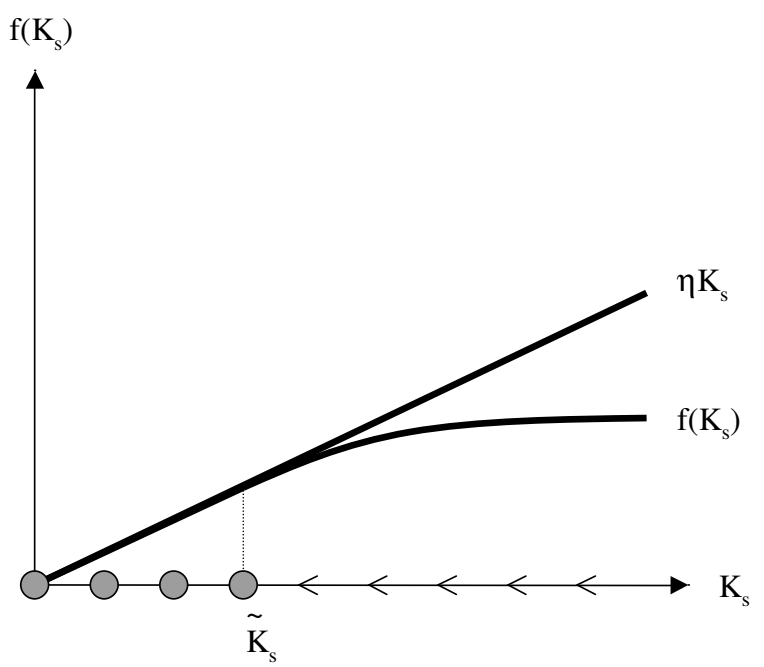

Fig. (18).

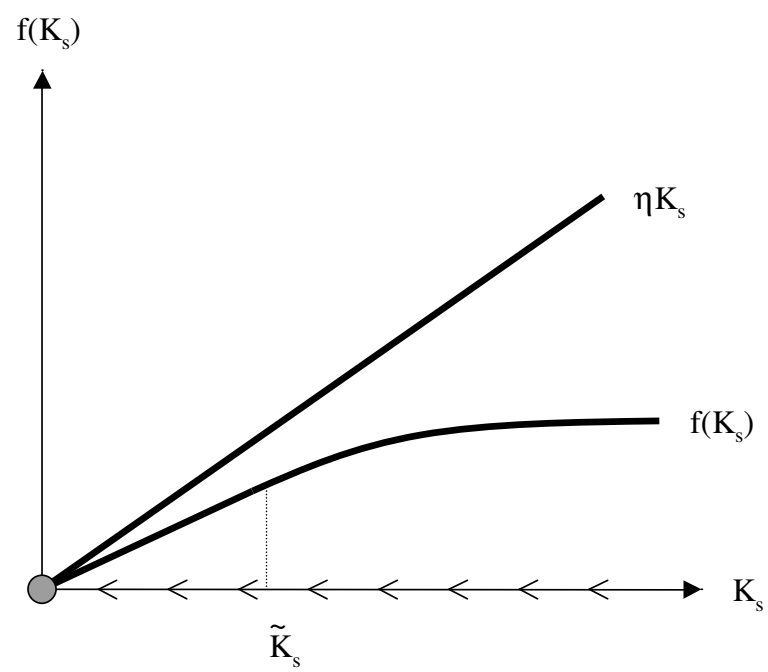

Fig. (19).

(b.3.3): $\gamma+\delta+\varepsilon<1$. In this last case (Fig. 20), there exists a point $\bar{K}_{s}>0$ which is an attractor for all $K_{s}>0$; $K_{s}=0$ is a repulsive fixed point.

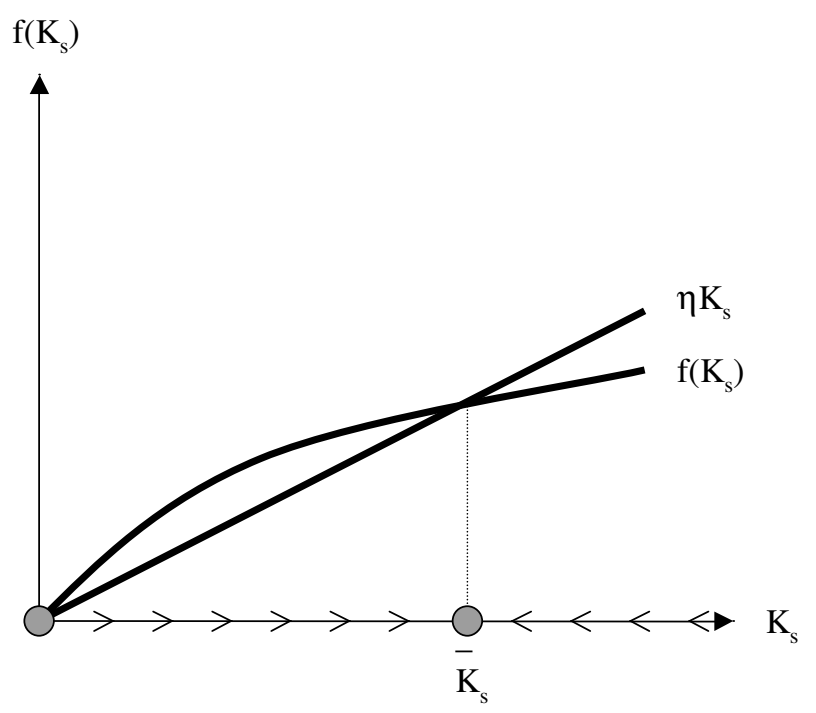

Fig. (20).

\section{REFERENCES}

Alesina, A., La Ferrara, E. (2000). Participation in heterogenous communities. The Quarterly Journal of Economics, CXV, 847-904.

Alesina, A., La Ferrara, E. (2002). Who trusts others? Journal of Public Economics, 85(2), 207-34.

Annen, K. (2001). Inclusive and exclusive social capital in the small-firm sector in developing countries. Journal of Institutional and Theoretical Economics, 157(2), 319-30.

Antoci, A., Sacco, P.L., Vanin, P. (2007). Social capital accumulation and the evolution of social participation. Journal of Socio-Economics, 36(1), 128-43.

Antoci, A., Sacco, P.L., Vanin, P. (2005). On the possible conflict between economic growth and social development. in gui B. and R. Sugden (eds.) Economics and Social Interaction: Accounting for Interpersonal Relations, Cambridge University Press, 150-73.

Arrow, K.J. (1971). Political and economic evaluation of social effects and externalities, in M.D. Intriligator (ed.) Frontiers of Quantitative Economics, Amsterdam, North Holland, 3-23.

Becker, G. (1965). A theory of the allocation of time. The Economic Journal, 75(299), 508.

Becker, G. (1981). A treatise on the family, Cambridge (MA) Harvard University Press.

Berg, J., Dickhaut, J., McCabe, K. (1995). Trust, reciprocity and social history. Games and Economic Behavior, 10 (1), 122-42.

Bowles, S., Gintis, H. (2002). Social capital and community governance. Economic Journal, 112(483), 419-36.

Buonanno, P., Montolio, D., Vanin P. (2008). Does social capital reduce crime? Journal of Law and Economics, forthcoming on vol. 52 , 2009.

Coleman, J. (1990). Social Capital, in J. Coleman, Foundations of social theory, Cambridge, Mass., and London, England, The Belknap Press of Harvard University Press.

Coleman, J. (1988). Social Capital in the creation of human capital American Journal of Sociology, 94S, S95-120.

Collier, P. (1998). Social capital and poverty, Social Capital Initiative Working Paper n.4, The World Bank.

Corneo, G., Jeanne, O. (1999). Social organization in an endogenous growth model. International Economic Review, 40 (3), 711-25.

Cornes, R., Sandler, T. (1984). Easy riders, joint production, and public goods. The Economic Journal, 94(375), 580-98.

Costa, D.L., Kahn, M.E. (2003). Understanding the American decline in social capital, 1952-1998, Kyklos, 56 (1), 17-46.

DiPasquale, D., Glaeser, E.L. (1999). Incentives and social capital: are homeowners better citizens? Journal of Urban Economics, 45, 35484.

Fukuyama, F. (1995). Trust. The social virtues and the creation of prosperity, London, Penguin.

Glaeser, E.L., Laibson, D., Sacerdote, B. (2002). An economic approach to social capital. Economic Journal, 112(483), 437-58.

Glaeser, E.L., Laibson, D., Scheinkman, J.A., Soutter, C.L. (2000). Measuring trust. The Quarterly Journal of Economics, CXV, 81146.

Gneezy, U., Rustichini, A. (2000). Pay enough or don't pay at all. The Quarterly Journal of Economics, CXV, 791-10.

Granovetter, M. (1973). The strength of weak ties. American Journal of Sociology, 78 (6), 1360-80.

Hirsch, F. (1976). Social limits to growth, Cambridge, Mass. Harvard University Press

Knack, S. (2003). Groups, growth and trust: cross-country evidence on the olson and putnam hipotheses. Public Choice, 117, 341-355.

Knack, S., Keefer P. (1997). Does social capital have an economic payoff? a cross-country investigation. Quarterly Journal of Economics, CXII, 1251-88.

Leung, A. (2002). Delinquency, social institutions, and capital accumulation. Journal of Institutional and Theoretical Economics, 158(3), 420-40.

Narayan, D. (1999). Bonds and Bridges: Social capital and poverty, Policy Research Working Paper Series 2167, The World Bank.

Nepal, M., Bohara, A.K., Berrens, R.P. (2007). The impacts of social networks and household forest conservation efforts in rural nepal. Land Economics, 83(2), 174-91.

Paldam, M., Svendsen G.T. (2000). An essay on social capital: looking for the fire behind the smoke. European Journal of Political Economy, $16,339-66$.

Putnam, R. (2000). Bowling Alone: The collapse and revival of american community, New York, Simon and Schuster. 
Putnam, R. (1995). Bowling alone: America's declinig social capital. Journal of Democracy, 6(1), 65-78.

Putnam, R. (1993). The prosperous community: social capital and public life. The American Prospect, 13, 35-42.

Routledge, B.R., von Amsberg, J. (2003). Social capital and growth. Journal of Monetary Economics, 50, 167-93.

Schiff, M. (1992). Social capital, labor mobility, and welfare. Rationality and Society, 4, 157-75.

Schiff, M. (1999). Labor market integration in the presence of social capital. Development Research Group, World Bank.

Schiff, M. (2002). Love thy neighbor: trade, migration and social capital. European Journal of Political Economy, 18(1), 87-107.
Spagnolo, G. (1999). Social relations and cooperation in organizations. Journal of Economic Behavior \& Organization, 38(1), 1-25.

Temple, J., Johnson, P. (1998). Social capability and economic growth. Quarterly Journal of Economics, 113 (3), 965-90.

Uhlaner, C.J. (1989). Relational goods and participation: incorporating sociability into a theory of rational action. Public Choice, 62(3), 253-85.

World Bank (2008). http://povlibrary.worldbank.org/ library/topic.php?topic= 4294 (Social Capital Library).

Zak, P.J., Knack, S. (2001). Trust and growth. The Economic Journal, 111, 295-321.

(C) Antoci et al.; Licensee Bentham Open.

This is an open access article distributed under the terms of the Creative Commons Attribution License (http://creativecommons.org/licenses/by/2.5/), which permits unrestrictive use, distribution, and reproduction in any medium, provided the original work is properly cited. 